\title{
New Apparatus for Direct Counting of $\beta$ Particles from Two-Dimensional Gels and an Application to Changes in Protein Synthesis due to Cell Density
}

\author{
Herbert L. Anderson \\ Theodore T. Puck" \\ E. Brooks Shera
}

DISCLAIMER

\begin{abstract}
This report was prepared as an account of work sponsored by an agency of the United States Government. Neither the United States Government nor any agency thereof, nor any of their employecs, makes any warranty, express or implied, or assumes any legal liability or responsibility for the accuracy, completeness, or usefulness of any information, apparatus, product, or process disclosed, or represents that its use would not iniringe privately owned rights. Keference herein to any specific commercial product, process, or service by trade name, trademark, manufacturer, or otherwise does not necessarily constitute or imply its endorsement, recommendation, of favoring by the United States Government or any agency thereof. The views and opinions of authors expressed herein do not necessarily state or reflect those of the United States Government or any agency thereof.
\end{abstract}

"Consultant at Los Alamos. Eleanor Roosevelt Institute for Cancer Research, 1899 Gaylord St., Denver, CO 80206. 


\title{
NEW APPARATUS FOR DIRECT COUNTING OF $\beta$ PARTICLES FROM TWO-DIMENSIONAL GELS AND AN APPLICATION TO CHANGES IN PROTEIN SYNTHESIS DUE TO CELL DENSITY
}

by

Herbert L. Anderson, Theodore T. Puck, and E. Brooks Shera

\begin{abstract}
A new method is described for scanning two-dimensional gels by the direct counting of $B$ particles instead of autoradiography. The methodology is described; results are compared with autoradiographic results; and data are presented demonstrating changed patterns of protein synthesis accompanying changes in cell density. The method is rapid and permits identification of differences in protein abundance of approximately $10 \%$ for a substantial fraction of the more prominent proteins. A modulation effect of more than 5 standard deviations, accompanying contact inhibition of cell growth, is shown to occur for an appreciable number of these proteins. The method promises to be applicable to a varicty of biochemical and genetic cxperiments designed to delineate changes in protein synthesis accompanying changes in genome, molecular environment, history, and state of differentiation of the cell populations studied.
\end{abstract}

\section{INTRODUCTION}

The combination of somatic cell genetics and recombinant DNA methodologies has made possible an enormous increase in the elucidation of the structure of the mammalian cell genome. However, what is perhaps the central unsolved problem of human genetics revolves around the following question: How are the cells of the different tissues, despite their possession of identical chromosomal and DNA structures. able to produce different and specific patterns of protein biosynthesis? An understanding of this process will illuminate the regulatory mechanisms that govern gene expression and the molecular dynamics of disease in the various tissues. Therefore, it tecomes necessary to find a way to study the spectrum of protein biosynthesis of different cell populations and to correlate with precision the changes in this pattern with changes in the DNA state, the molecular environment, and the differentiation history of the cell. 
The two-dimensional (2D) gel technique pionecred by O'Farrell offers great power in clucidating protein biosynthetic patterns because it permits us to cxamine large numbers of the proteins synthesized by any cell population. We undertook our study 1) to eliminate the need for using autoradiography as a means of visualizing the deposition points, in the gel, of the peptides containing radioactively labeled amino acids and 2) to obtain precisc measurements of changes in protein quantity. The cxposure of autoradiographic films can be time-consuming, and a lincar rclationship between the amount of film blackening and the quantity of peptide deposited is obtained only over a relatively limited range of intensitics, making quantitative comparisons difficult. Quantification by autoradiography requires a scrics of autoradiographs with different exposure times. ${ }^{2}$

We describc here a method for detecting and quantilying radiolabeled peptides in $2 \mathrm{D}$ gels by counting the $\beta$ particles dircetly. The methodology is described; its results are compared with those obtained by the autoradiographic technique; and some representative biological findings are reported. In this study we have concentrated on the group of the most abundant proteins synthesized by Chinese hamster ovary (CHO) cells in tissue cultures. The examination of $a$ larger number of such proteins is straightforward and is being implemented, but it requires considerably more eflort. The purpose of this paper is to demonstrate the general approach.

\section{METHODOLOGY}

\section{Preparation and Treatment of the Cells}

A standard tissue culture dish containing cells is trypsinized, and $10^{5}$ cells arc innoculated into a new dish $(100-\mathrm{mm}$ diameter) to which is added $10 \mathrm{ml}$ of $\mathrm{Fl}$ enriched with $8 \%$ fetal calf serum (FC). This dish is incubated at $37^{\circ} \mathrm{C}$ for 72 hours, at which point the cells are still growing exponentially. An aliquot of $2 \times 10^{5}$ cells is then platet onto a $35-\mathrm{mm}$ culture dish in $1 \mathrm{ml}$ of standard medium FI2FC8 and incubated for an additional 18 hours. If drugs arc to be added to the culture, the medium is removed at that time, the cell monolayer is washed with $1 \mathrm{ml}$ of prewarmed F12FCM8 (FCM is dialyzed fetal calf scrum), and fresh medium containing the agents to be tested is added. The dishes are then incubated for the period specified in each cxperiment.

Radioactive labeling is carricd out by removing the medium from each dish and washing the cell monolaycr with $1 \mathrm{ml}$ of growth medium from which methioninc has been deleted. Onc $\mathrm{ml}$ of the same growth medium, with $100 \mu \mathrm{Ci} / \mathrm{ml}$ of ${ }^{35} \mathrm{~S}$-methioninc is added to cach dish, and incubation is continucd for one hour. Alternatively, 
${ }^{14} \mathrm{C}$-labeling with one or more amino acids may be employed with appropriate adjustments to the medium. Any drugs used in the experiments are maintained throughout all medium changes.

The cell lysate is prepared according to the method of Garrels. ${ }^{2}$ The lysate is immediately frozen at $-70^{\circ} \mathrm{C}$ and stored at that temperature until it is placed in the isoclectric focusing gel. The 2D gel electrophoresis is then carried out according to the method of O'Farrell $^{1}$ with the modification of Duncan and Hershey. ${ }^{3}$ Labeled protein mass standards are added to cach gel to furnish calibration of the molecular weight gradient. The $\mathrm{pH}$ gradient of the first dimension is determined by slicing the tube gel in $1-\mathrm{cm}$ sections, placing each in $5 \mathrm{ml}$ of distilled water, and measuring the corresponding $\mathrm{pH}$ of each solution.

\section{Multiwire Chamber}

The $B$ particles from the gel are counted directly with a position-sensitive multiwire proportional chamber. A strong (1.9-tesla) magnetic field is used to keep the $B$ particles from spreading away from their point of origin. The $B$ particles from ${ }^{14} \mathrm{C}$ or ${ }^{35} \mathrm{~S}$, used in the radiolabel, are of such low energy that they follow the magnetic lines of force in tight spirals, keeping the displacement from the point of origin within 400 microns. Figure 1 is a schematic representation of the arrangement showing the helical path taken by the $\beta$ particles as they emerge from the gel. The $\beta$ particles ionize the gas and produce secondary electrons, which are drawn toward the anode. These electrons multiply rapidly by further ionization, producing an avalanche when they reach the high electric field near an anode wire. As a result, pulses arc induced in the nearby cathode wires. The pulses decrease in size with increasing distance from the avalanche, as shown in the figure. Each cathode wire is provided with its own amplifier and discriminator for the readout of the location of the $\beta$ particle. The circuitry ${ }^{4}$ determines the center of the set of wires with pulses above a fixed threshold and uses this as the coordinate of the $\beta$ particle that is being recorded. For each $B$ particle, the $\mathrm{x}$ and $\mathrm{y}$ coordinates are specificd to the half-wire. The wire number is integral or half-integral according to whether the number of wires hit is odd or even. The wire spacing is $1.5 \mathrm{~mm}$, and the collection area, or bin size, is $750 \times 750 \mu \mathrm{m}^{2}$. There are 128 wires for each coordinate or, equivalently, 256 bins: thus, there are 65,536 bins in all. The memory capacity is sufficient to store up to 65,536 events at each location.

The multiwire proportional chamber is mounted inside a brass box. The box has a thin Mylar window that serves as a gas seal. The gel to be measured is 


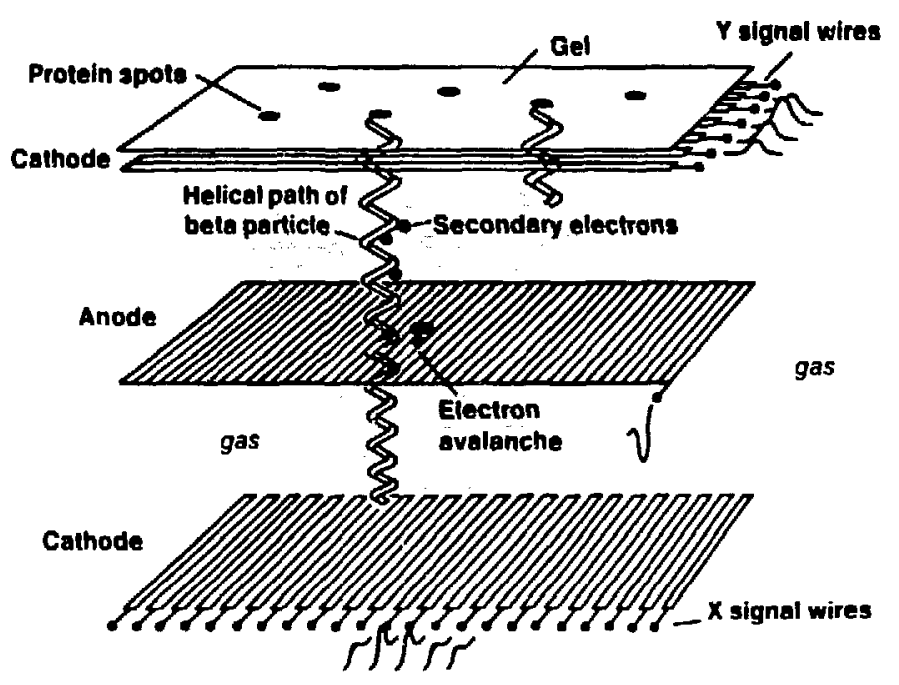

Fig. 1. Schematic view of the $2 \mathrm{D}$ readout multiwire proportional chamber. The $x$ and $y$ coordinates of each $\beta$ particle emitted from the gel are read out from two cathode wire planes, one above and one below the anode wire plane. $A$ strong magnetic field keeps the $\beta$ particle from spreading from its point of origin by constraining it to move in a tight spiral. The $\beta$ particle ionizes the gas in the chamber, releasing secondary electrons that drift to the anode, where they develop a highly localized avalanche. This, in turn, induces voltage pulses in the nearby cathode wires above and below. The electronic readout circuitry locates the center of the pulse array and stores it in the appropriate bin in memory.

mounted on a brass lid and set in an opening in the brass box on top of the Mylar window. A large scintillation counter placed underneath the chamber serves as a cosmic ray veto. Once the gel and its cover are in position, a large C-magnet, mounted on a cart, is rolled into place so that the chamber lies between the poles. The poles are 25 by $25 \mathrm{~cm}^{2}$ in area with a $3.5-\mathrm{cm}$ gap. The magnet, which has water-cooled coils, provides a magnetic field of 1.9 tesla using $10 \mathrm{~kW}$ of power.

\section{Counting}

Under normal circumstances the gels are loaded with $10^{6}$ disintegrations per minutu of ${ }^{35} \mathrm{~S}$-methionine-labeled protein. Gels prepared with these proteins show a total activity of about 40,000 counts per minute, after correction for decay (87.2-day half-life), for an overall efficiency of about $4 \%$. Some radioactivity is lost to the buffer in preparing the gel; some is lost by virtue of the fact that only a part of the entire protein $\mathrm{pH}$ and mass ranges is retained. Together, these losses amount to $30 \%$. 
One-half of the $\beta$ particles are emitted in the upper hemisphere, away from the chamber. A large fraction of the remainder, about $70 \%$, is absorbed in the thickness of the gel before reaching the chamber. In addition, although the chamber itself is rather efficient, there are losses in the Mylar window and in the wires of the upper cathode plane. Moreover, because of the high threshold needed for resolution purposes, the low-energy end of the $\beta$ spectrum is missed.

\section{Calibration}

The sensitivity of the chamber over its useful area is not as uniform as one would like, partly because no provision is made for equalizing the gain of the individual wires by voltage adjustment. Moreover, the signal from a $\beta$ particle located between two adjacent wires is divided between the two, the closer wire receiving the larger part of the signal. This effect can be readily seen in a gel with a uniform distribution of radioactivity: the half-integral bins record lower counts than do the integral bins. We compensate for these variations by standardizing the count in each bin with the count obtained from a gel made with a uniform mixture of ${ }^{14} \mathrm{C}$-labeled material. It has been our practice to collect a total of $10^{6}$ counts for each gel under measurement and to standardize these with a uniform gel measurement of $5 \times 10^{7}$ counts.

\section{Contour Plots}

One way of displaying the data is in the form of a $2 D$ contour plot that gives the intensity as a function of wire position as shown in Fig. 2. Each successively lower contour is at a level 0.8 of the one above it. An eight-wire by eight-wire segment enclosing three proteins is shown in the figure. The protein on the right carries $0.24 \%$ of the radioactivity deposited on the gel; the one on the left carries $0.22 \%$; the third, in the center of the lower part of the figure, carries $0.04 \%$. The total count on the gel was 106; maximum count was 519 at wire coordinates $x=86.5$, $y=77.5$, corresponding to bin coordinates $x=173, y=155$. The lowest contour shown is at the level of 51 counts per bin.

It is easy to see (by looking at the size of the third contour) that the full width at half maximum resolution is $1.5 \mathrm{~mm}$, equal to the wire spacing. Proteins of low abundance are suppressed in this display because contours below the 52-count/bin level were ignored. 


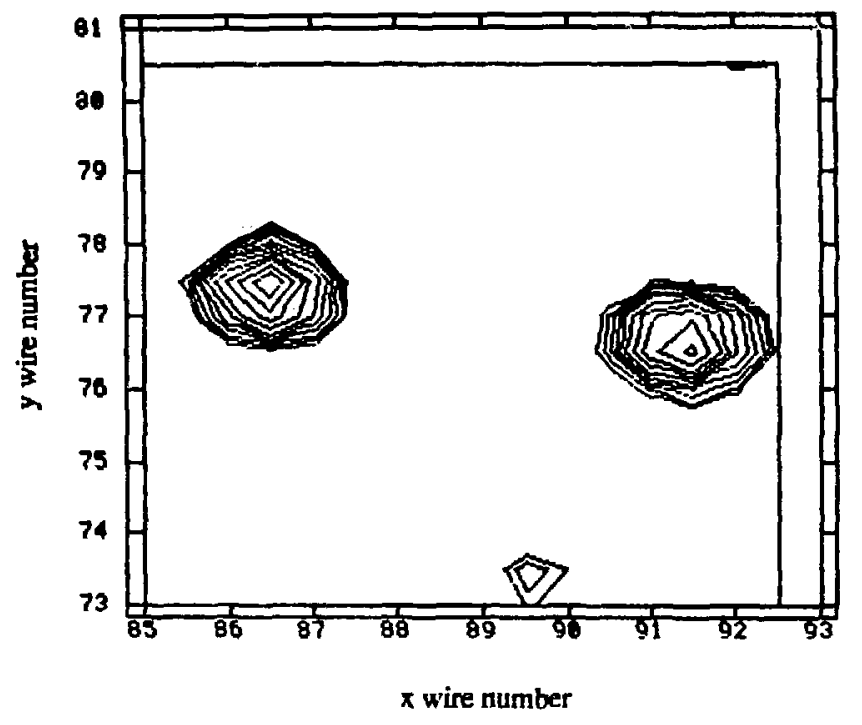

Fig. 2. Contour plot of the radioactivity of three protein peaks in a $12-\mathrm{mm}$ by $12-\mathrm{mm}$ region of the gel. Each successively lower contour is at a level 0.8 of the one above it. The location is given by the wire number. The wire spacing is $1.5 \mathrm{~mm}$. The maximum count is 510 ; the lowest, 55 .

A larger segment, 32 by 32 wires ( 48 by $48 \mathrm{~mm}^{2}$ ), shown in Fig. 3, displays 35 proteins and includes actin, the most prominent protein of all. Actin carries $6 \%$ of the radioactivity in the gel and appears at the position ( $x$-wire, $y$-wire) $=(100.5,63.5$ ). Because of its many components, actin is not a simple peak and spreads over a considerable range of $\mathrm{pH}$. By summing the count in all of the bins assigned to this peak, we can readily obtain the total count.

In Table 1 the peaks shown in Fig. 3 are listed in order of decreasing abundance. We give the peak number, the peak count, the $x$-position, the $y$-position, and the abundance of the protein in parts per $10^{5}$ from the sum of counts under the peak (after background subtraction) compared to the total count for the gel as a whole, usually $10^{6}$.

Note that actin is the only protein carrying more than $1 \%$ of the total gel radioactivity. In a typical gel of the present experiment, there were 6 proteins with abundance between $1 \%$ and $0.5 \%, 111$ between $0.5 \%$ and $0.1 \%, 198$ between $0.1 \%$ and $0.05 \%$, and 417 between $0.05 \%$ and $0.01 \%$. At the $0.01 \%$ level we are dealing with peaks having about 100 counts. We can easily increase this to 1000 by counting ten times as long ( 10 hours), but we have not found it profitable to do so at this stage of our work. 


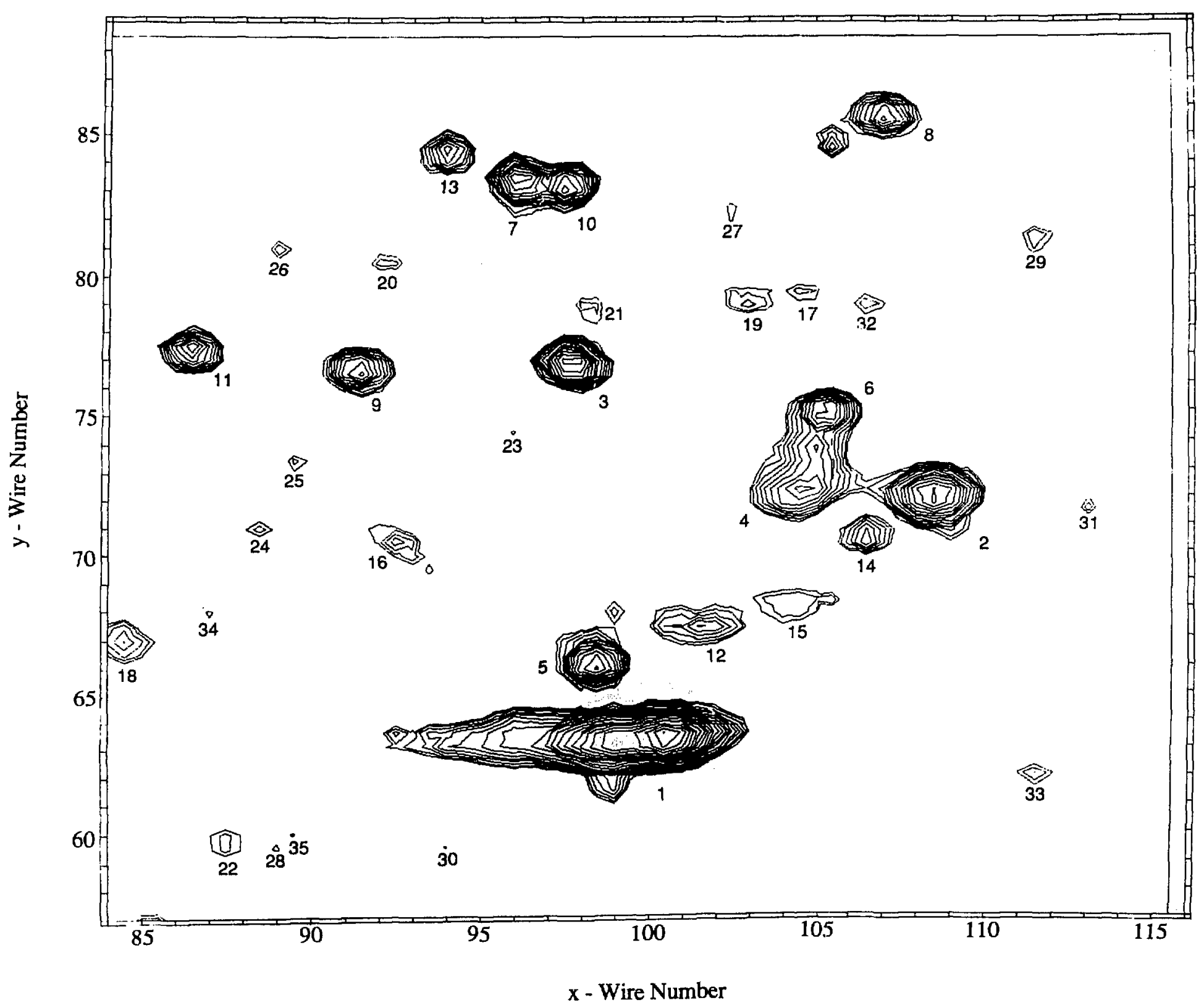

Fig. 3. Contour plot of $48-\mathrm{mm}$ by $48-\mathrm{mm}$ region of the gel. The proteins and their abundances are listed in Table 1. Note the unequal scales in $x$ and $y$. The numerals are peak numbers. 
TABLE 1

PEAKS SHOWN IN FIGURE 3

\begin{tabular}{|c|c|c|c|c|}
\hline Peak No. & Peak Count & $\mathrm{x}$-Wire & $y$-Wire & $\begin{array}{l}\text { Abundance } \\
\left.\text { (parts } / 10^{5}\right)\end{array}$ \\
\hline 1 & 5125 & 100.5 & 63.5 & $a_{5730}$ \\
\hline 2 & 956 & 108.5 & 72.0 & $\bar{b}_{867}$ \\
\hline 3 & 1079 & 98.0 & 77.0 & 659 \\
\hline 4 & 446 & 104.5 & 72.5 & 635 \\
\hline 5 & 764 & 98.5 & 66.0 & 531 \\
\hline 6 & 616 & 105.5 & 75.5 & 439 \\
\hline 7 & 692 & 96.0 & 83.5 & 430 \\
\hline 8 & 409 & 107.0 & 85.5 & 339 \\
\hline 9 & 498 & 91.5 & 76.5 & 330 \\
\hline 10 & 636 & 97.5 & 83.0 & 280 \\
\hline 11 & 541 & 86.5 & 77.5 & 276 \\
\hline 12 & 201 & 101.5 & 67.5 & 271 \\
\hline 13 & 354 & 94.0 & 84.5 & 245 \\
\hline 14 & 262 & 106.5 & 70.5 & 240 \\
\hline 15 & 125 & 104.5 & 68.5 & 219 \\
\hline 16 & 160 & 92.5 & 70.5 & 206 \\
\hline 17 & 124 & 105.0 & 79.5 & 171 \\
\hline 18 & 157 & 84.5 & 67.0 & 163 \\
\hline 19 & 128 & 103.0 & 79.0 & 161 \\
\hline 20 & 119 & 92.0 & 80.5 & 155 \\
\hline 21 & 124 & 98.0 & 79.0 & 149 \\
\hline 22 & 101 & 87.5 & 60.0 & 140 \\
\hline 23 & 108 & 96.0 & 74.5 & 131 \\
\hline 24 & 107 & 88.5 & 71.0 & 120 \\
\hline 25 & 105 & 89.5 & 73.5 & 108 \\
\hline 26 & 113 & 89.0 & 81.0 & 107 \\
\hline 27 & 94 & 102.5 & 82.5 & 97 \\
\hline 28 & 86 & 89.0 & 59.5 & 93 \\
\hline 29 & 104 & 111.5 & 81.5 & 91 \\
\hline 30 & 85 & 94.0 & 59.5 & 90 \\
\hline 31 & 69 & 113.0 & 71.5 & 87 \\
\hline 32 & 116 & 106.5 & 79.0 & 84 \\
\hline 33 & 103 & 111.5 & 62.0 & 83 \\
\hline 34 & 86 & 87.0 & 68.0 & 76 \\
\hline 35 & 84 & 89.5 & 60.0 & 75 \\
\hline
\end{tabular}




\section{Peak Finding and Matching}

The large number of data points comprising cach gel image (65,536 16-bit bins) requires that computer methods be used to locate and quantify the peaks that correspond to proteins on the gel. Because we normally desire to compare the protein compositions of several biological samples, we employ automatic methods to match and tabulate the protein spot patterns and abundances from the series of gels used in a typical experiment. Each gel image may yield 300 to 1000 individual protein spots, depending upon the counting time and the threshold sensitivity setting of the peak-finding sof tware.

In general, automatic peak finding and pattern matching present serious problems because of streaking and distortion of the protein pattern from one gel to the next. Although these problems can be reduced by careful, consistent samplepreparation and electrophoresis procedures, gel variability has not yet been entirely eliminated. Computer alogorithms for $2 \mathrm{D}$ gel analysis, which address these problems, are the subject of an extensive literature. ${ }^{2}, 5-10$

We have relied heavily on the ELSIE software developed by M. J. Miller, A. D. Olson, and collaborators at the National Institutes of Health (NIH), both for inspiration and for much of the actual C-language code used in the present analysis. Peaks are located by identifying regions in which the second derivative of the data, computed using a template of a specified shape, exceeds a threshold value. This scheme works well for peaks that are relatively isolated but may fail to resolve peaks that overlap. The software attempts to resolve such cases by progressively raising the detection threshold to determine whether a potential single peak will divide into two or more distinct peaks. The count under each peak is estimated by summing the background-subtracted counts in those contiguous bins for which the count exceeds a specified fraction of the peak height.

Matching of identical peaks in a series of gels is determined from the geometrical arrangement of nearby peaks and is verified by demanding that neighboring pcaks correspond to a degree that is well beyond chance probability. A listing of the matching peaks may include a multiplicity of peaks if these are all located within a specified displacement distance from the peaks they are supposed to match. In this case the several pcaks will be assigned a common "master peak" number.

The principal modifications we have made to the NIH software have been in the following areas: 1) data precision (the NIH software deals with optical densitometer data rather than direct beta counts); 2) methods of correcting for gel background and streaks (we use an adaptation of the "rolling pin" methods of Skolnick et al.; 9 
3) method of computing peak total count; 4) methods for confirming ("filtering") protein total count variations by automatically intercomparing two or more gels madc from the same biological sample (see "Filtering"); and 5) data display and output (our primary output devices are the bit-mapped displays of the Apple Macintosh computer and the Sun workstation, used with the Apple LaserWriter).

A special burden is placed on our analysis software by the limited spatial resolution of the wire chamber (each bin covers 750 microns). Autoradiographic film is normally scanned with a resolution of 100 to 200 microns, so a typical small protein spot with a diameter of 500 to 1000 microns is sampicd at several points across its intensity profile. With coarser resolution, such a protein may appear in only a single bin. Thus, peaking-finding and area-calculation algorithms that rely on peak shape or intensity gradients may encounter difficulty with wire chamber data. Although we claim no ideal solution to this problem, we have been most successful with procedures that emphasize accurate background removal before peak detection and quantification. A detailed description of our data-analysis procedures is beyond the scope of this report but will be given in a separate publication.

\section{Filtering}

As a practical measure we have concentrated our attention on the more prominent proteins, which are easily measured. To measure complex peaks or to deal successfully with artifacts due to streaking in the gel would require much more time and effort. Moreover, because the number of peaks increases rapidly as the selection threshold is lowered, it becomes increasingly more difficult to measure the peaks accurately because of overlap and background problems.

With a given setting of the threshold, there are always peaks that fall below this threshold in the comparison gels and are missed. In view of this problem, we introduced a useful filtering technique, preparing pairs of gels having equal aliquots of the same proteins. We prepared four such pairs, eight gels in all, of biologically equivalent proteins. The proteins on these gels were compared, and only where the same protein could be identified on all eight gels was it assigned a common master peak number and taken for further consideration, at least in the first round of analysis. For each master peak, the total count on all of the eight gels was measured and the standard deviation computed. This gave us the basis for selecting those proteins showing the effect we were looking for.

For the purposes of the present work it turned out to be practical to set the threshold of intensity so that about 350 protein peaks were measured. Of these, some 
200 survived the filter, were assigned a master peak number, and were made available for further analysis. We also used a lower threshold setting, which yielded about twice the number of peaks, but in the present work this setting was used only for verification purposes.

\section{Catalog of the Most Prominent Peaks}

It is useful to identify some 25 of the most prominent peaks in each of the measured gels. These serve to verify that the gel manufacturing and measuring procedures have been properly carried out and are suitable for obtaining a reliable measurement. Listed in Table 2 are 23 of the most abundant proteins obtained from a culture of CHO-Kl cells grown to a density of $2 \times 10^{5}$ in a $35-\mathrm{mm}$ culture dish. We measured eight gels, two from each set of proteins extracted from four different cultures. We list only those proteins for which a match was found in all eight gels and to which a master peak number could be assigned. In all cases the same proteins were also found in a second set of gels from cells grown to a density of $2 \times 10^{6}$.

In Table 2 the $(x, y)$ positions are for gel la. The average abundance and its standard deviation are given for each master peak. The ordering, except for minor perturbations, is according to decreasing molecular weight. The first eight peaks in Table 1 also appear in Table 2. The abundance values differ somewhat because in the former the values refer to the measurements on a single gel, while in the latter the values given are the averages of eight measurements.

For each gel measured, a spot graph is prepared. Figure 4 is the spot graph for gel la. Thus, the locations of the paaks listed in Table 2 are shown in Fig. 4, the spot locations corresponding to the coordinates given in the table. The spots are represented by circles, which are shaded to indicate the level of protein abundance and sized to indicate the actual spot size. The data from each gel are combined, according to the scheme outlined under "Filtering," into the single master spot list shown in Table 2. As an example of the analysis that led to the numbers given in Table 2, we give, in Table 3a, the listing of the matched set of peaks that corresponds to master peak 83 .

The peaks listed in Table $3 a$ are the matched peaks assigned to master peak 83 from the set of eight (odd-numbered) gels made from cells grown on a 35-mm-diameter culture dish to a density of $2 \times 10^{5}$. The designators a and $b$ refer to the two members of the pair of gels made from aliquots of the same proteins in each of the 
TABLE 2

\section{CATALOG OF PROMINENT PEAKS \\ OBTAINED FROM A CULTURE OF CHO-KI CELLS}

Master

Peak No. ${ }^{a}$

35

54

55

57

58

76

77

83

121

126

130

137

138

147

148

170

175

181

184

186

188

191

241
Bin No.

\begin{tabular}{cc}
$\mathrm{x}$ & $\mathrm{y}$ \\
\hline 194 & 191
\end{tabular}

$\begin{array}{ll}95 & 184\end{array}$

$87 \quad 184$

$212 \quad 182$

$208 \quad 182$

$213 \quad 172$

$191 \quad 168$

$187 \quad 170$

$195 \quad 155$

$112 \quad 155$

$210 \quad 152$

$83 \quad 151$

$\begin{array}{ll}68 & 151\end{array}$

$216 \quad 146$

$208 \quad 146$

$149 \quad 136$

$196 \quad 133$

$131 \quad 134$

$201 \quad 131$

$206 \quad 128$

$\begin{array}{ll}184 & 128\end{array}$

$198 \quad 127$

$82 \quad 105$
Isoelectric

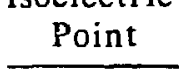

5.76

6.99

7.09

5.39

5.50

5.39

5.79

5.89

5.76

6.79

5.45

7.12

7.33

5.30

5.48

6.34

5.74

6.55

5.63

5.53

5.91

5.70

7.13
Mo. Wt.

(kg/mole)

121

106

107

101

101

83

74

78

60

59

56

55

56

52

52

46

45

45

43

43

43

43

35
Average

Abundance

(parts/105)

$443 \pm 81$

$184 \pm 11$

$83 \pm 6$

$879 \pm 120$

$402 \pm 46$

$257 \pm 20$

$595 \pm 90$

$150 \pm 11$

$659 \pm 43$

$232 \pm 12$

$575 \pm 34$

$349 \pm 12$

$352 \pm 14$

$858 \pm 17$

$651 \pm 29$

$604 \pm 15$

$531 \pm 24$

$362 \pm 11$

$2401 \pm 479$

$149 \pm 23$

$181 \pm 62$

$3000 \pm 363$

$334 \pm 16$

$\bar{a}$ Peaks $184,186,188$, and 191 are part of the actin complex and are collectively designated peak 1 in Fig. 3 and Table 1. Peaks 147, 121, $148,175,130,77$, and 76 appear as peaks 2 through 8 , respectively, in Table 1. 


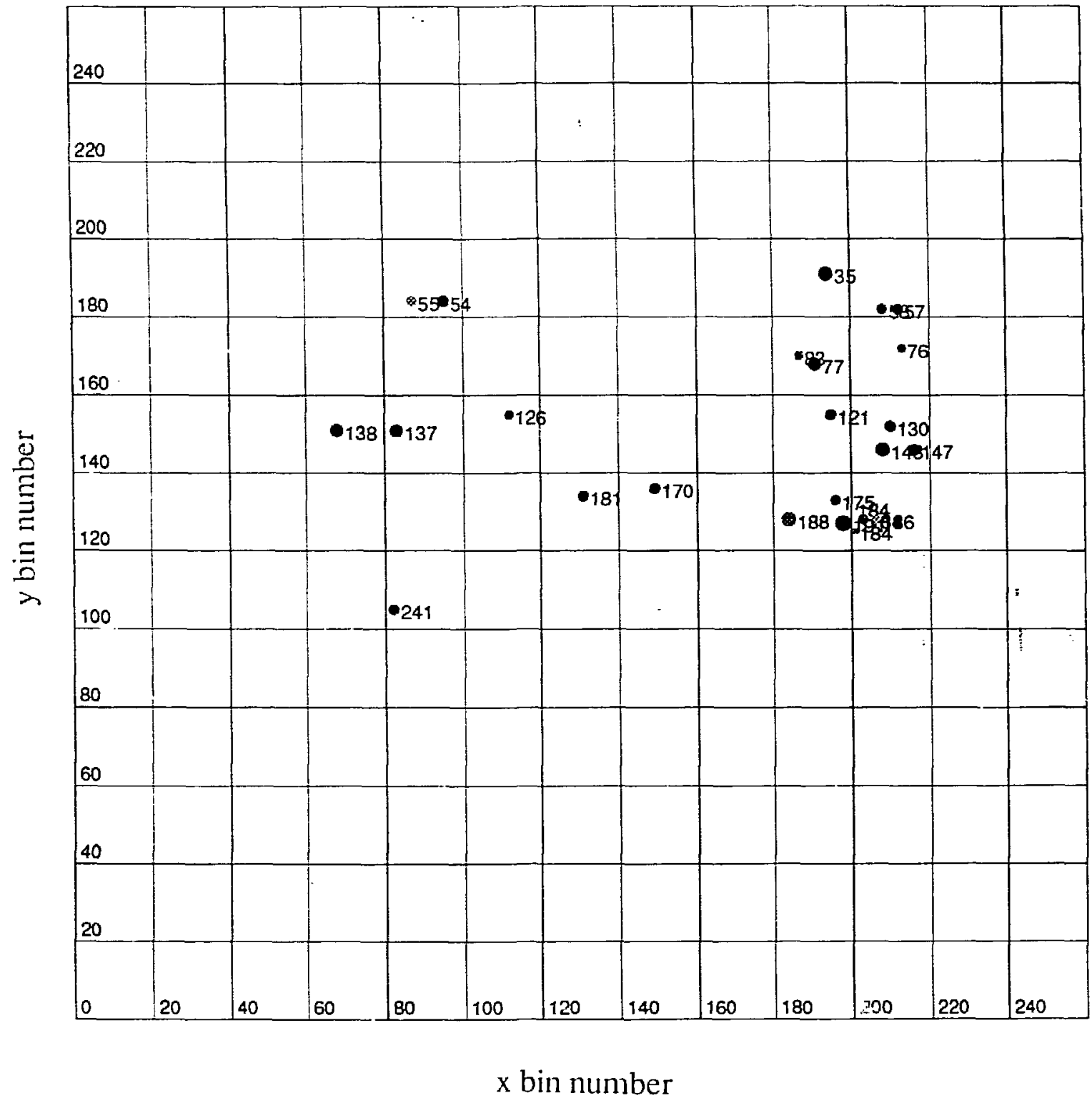

Fig. 4. Spot graph showing the location of the 23 most prominent proteins listed in Table 2. 
(a) Gels Made from Cells Grown to Density $2 \times 10^{5}$

\begin{tabular}{|c|c|c|c|c|}
\hline Gel No. & Peak No. & $x^{\operatorname{Bin}}$ & No. & $\begin{array}{r}\text { Total Count } \\
\text { (thousands) }\end{array}$ \\
\hline la & 89 & 187 & 170 & 1.89 \\
\hline $1 \mathrm{~b}$ & 81 & 193 & 175 & 1.36 \\
\hline $3 a$ & 89 & 190 & 171 & 1.61 \\
\hline $3 b$ & 88 & 190 & 175 & 1.77 \\
\hline $5 a$ & 76 & 190 & 168 & 1.68 \\
\hline $5 b$ & 79 & 188 & 175 & 1.54 \\
\hline $7 a$ & 66 & 186 & 168 & 1.19 \\
\hline $7 \mathrm{~b}$ & 73 & 190 & 173 & 0.95 \\
\hline
\end{tabular}

a Average count: $(1.50 \pm 0.11) \times 10^{3}$.

(b) Gels Made from Cells Grown to Density $2 \times 10^{6}$

\begin{tabular}{|c|c|c|c|c|}
\hline Gel No. & Peak Nò. & & o. & $\begin{array}{r}\text { Total Count } \\
\text { (thousands) }\end{array}$ \\
\hline $2 a$ & 86 & 185 & 171 & 3.24 \\
\hline $2 b$ & 76 & 191 & 176 & 3.05 \\
\hline $4 a$ & 89 & 185 & 167 & 3.02 \\
\hline $4 b$ & 107 & 186 & 175 & 4.31 \\
\hline $6 \mathrm{a}$ & 97 & 187 & 170 & 3.08 \\
\hline $6 \mathrm{~b}$ & 84 & 188 & 175 & 3.03 \\
\hline $8 a$ & 76 & 187 & 172 & 2.86 \\
\hline $8 \mathrm{~b}$ & 76 & 184 & 173 & 2.39 \\
\hline
\end{tabular}


four cultures that were run. Table $3 b$ is a list of the matched peaks from the cight (even-numbered) gels made from cells grown to a density of $2 \times 10^{6}$.

The peak numbers given in Tables $3 a$ and $3 b$ are those assigned by the peak rinder as it identifies peaks on surveying the individual gels. The peak matcher makes many attempts to find the peaks belonging to the same protein in the individual gels. It assigns a master peak number, in this case 83 , when it successfully finds a match in all eight gels. As we have mentioned, its success rate is about $60 \%$. Much of the failure to find matches reflects the likelihood that one or more of the matching peaks fail to meet the threshold criteria. We can verify when this occurs by relaxing these criteria. Note the variation in peak number and in the $x, y$ coordinates of the individual peaks. We cannot depend on coordinates alone to identify the matches. The matching process depends heavily on the similarity of the surrounding pattern of spots. Mismatches occur, but they are rciatively rare.

It is essential to our method to repeat the ineasurement many times. The abundance given is the mean of many measurements, and its standard deviation can be calculated and used as a measure of the uncertainty of the measurement. We have adopted an eight-gel protocol in which we make eight measurements of protein abundance in cells of the same biology, two gels from each of four cell cultures. We look for an effect by calculating the ratio of the means and assigning an error by the usual rule of compounding the standard deviations. 11

Ih Fig. 5 we give a histogram of the fractional rms deviations of the 196 proteins for which master peak numbers could be assigned. The measurements exhibit only an approximate gaussian distribution. For a variety of reasons, some proteins are difficult to measure reliably. These give an anomalously high rms deviation. In view of this difficulty, we identify proteins that show an appreciable modulation effect by requiring that the abundance ratio ( $R$ ) or its reciprocal ( $1 / \Omega$ ) be greater than 1.6 and that these quantities differ from 1 by more than 5 standard deviations, instead of the usual 3. The probability that a 5-standard-deviation effect will occur by chans is small enough to make this value a useful criterion for our purposes. In the case of peak 83 , presented in Tables $3 \mathrm{a}$ and $3 \mathrm{~b}$, the ratio $\mathrm{R}\left(2 \times 10^{6} / 2 \times 10^{5}\right)=2.09 \pm 0.20$. Thus, the apparent crror is about $10 \%$, and the deviation from 1 is 5.5 standard deviations, a clear cell-density effect according to our criteria. 


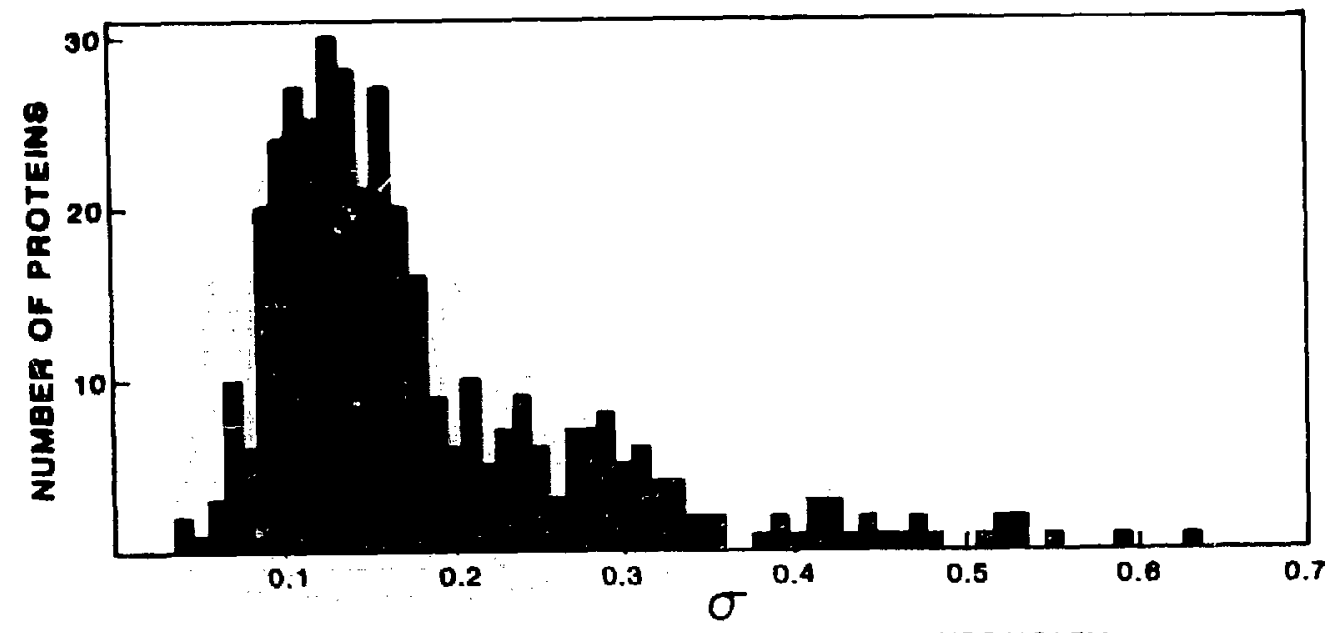

FAACTIONAL R.M.S. DEVIATION IN INTENSITY

Fig. 5. Histogram of the fractional rms deviation in protein abundance from measurements with the eight-gel protocol.

\section{COMPARISON WITH AIJTORADIOGRAPHY}

We compare our measurements with autoradiography by showing, in Fig. 6, a section of the autoradiograph thai corresponds to the contour plot of Fig. 3. The correspondence is quite good. Most of the spots that appear in the autoradiograph show up clearly in the contour plot. Some weak spots in the autoradiograph do not show in the contour plot, primarily because we have, for clarity, deleted the contours for low-abundance proteins in order to show only the more intense spots.

The resolution in the autoradiograph is about twice as good as that in the contour plot. However, the deficiency in resolution is not inherent in the direct $\beta$-particle counting method, and we have in progress an improved design that will provide much better resolution. Further, for many proteins resolution is not a problem as Fig. 3 makes clear. The importance of our method is that we can measure more directly and with greater precision the changes in protcin abundance that play an essential role in a wide class of biological processes.

\section{REPRESENTATIVE STUDY: EFFECT OF CELL DENSITY}

It is well known that many cell lines cease to divide when a monolayer has been formed. ${ }^{12}$ This is an inhibition by contact, a density-dependent form of regulation. With $2 \times 10^{5}$ cells on a 35 -mm-diameter culture dish, the cells are growing exponentially. When the number reaches $2 \times 10^{6}$, the rate of growth has leveled off. To see the effect, we looked for changes in the abundance of proteins from cells grown to high density $\left(2 \times 1^{6}\right)$ compared to those from cells growing exponentially at 


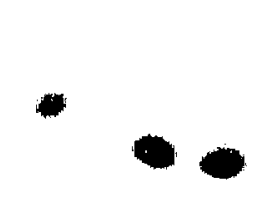

- a
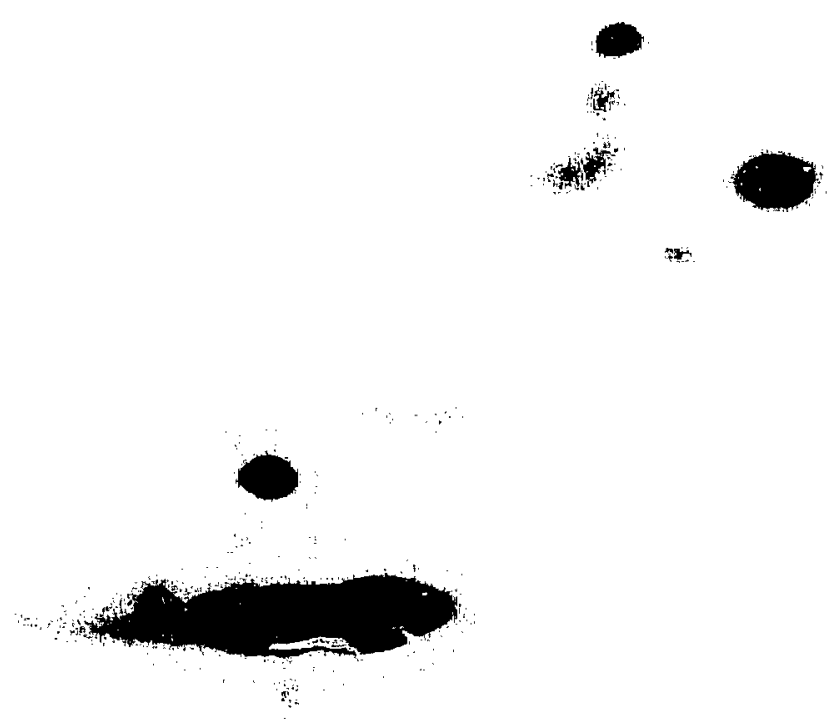

Fig. 6. Portion of an autoradiograph for comparison with the contour plot of Fig. 3. 
lower density $\left(2 \times 10^{5}\right)$. The results were striking. However, a comparison of densities $2 \times 10^{4}$ and $2 \times 10^{5}$, both on the exponential part of the growth curve, showed a much smaller effect.

The density effect can be seen very clearly when one compares the scatter plots of Figs. $7 \mathrm{a}$ and $7 \mathrm{~b}$. Here we plot the abundance of proteins obtained from cells grown to a density of $2 \times 10^{5}$ on the abscissa. The abundance of the same proteins is plotted along the ordinate for density $2 \times 10^{4}$ in Fig. $7 \mathrm{a}$ and for density $2 \times 10^{6}$ in Fig. 7b. We usc + to denote those proteins for which $R \leq 1.6$ or $1 / R \leq 1.6$. If these limits are exceeded, we show the master peak number. 1t is clear that the spread of these quantities from 1 is much greater in $7 \mathrm{~b}$ than in $7 \mathrm{a}$. Moreover, the number of proteins showing master peak numbers is apprcciably greater in $7 \mathbf{b}$, where there are 40 , than in 7a, where there are only 10 . When we apply the further criterion of a 5-standard-deviation effect, 21 proteins remain in $7 \mathrm{~b}$ and only 3 in $7 \mathrm{a}$.

The location of the proteins for which there was an enhancement with $R \geq 1.6$ or a diminution with $1 / R \geq 1.6$ is shown in Fig. 8. Peak numbers assigned to those for which the effect was more than 5 standard deviations are underlined in Fig. 8 and listed in Tables $4 a$ and $4 b$. The abundance given in these tables is the fraction, in parts per $10^{5}$, of the radioactivity under the peak compared to the total on the gel. These tables indicate our best candidates for the density-modulation effect.

The eighth column of Tables $4 a$ and $4 b$ gives the ratio of the abundances for cell densities $2 \times 10^{6}$ and $2 \times 10^{5}$. The ratio and its standard deviation are for the average of eight gels. The peaks listed in Tables $4 a$ and $4 b$ are those for which the effect was greater than 5 standard deviations, with $R \geq 1.6$ and $1 / R \geq 1.6$. In these lists there are 10 and 11 such proteins, respectively.

\section{CONCLUSIONS}

Our method of counting directly the $\beta$ particles from $2 D$ gels enables us to determine, to a precision of about $10 \%$, the modulation of protein intensity due to biological factors. This precision is limited to a fraction of the proteins that appear separated on the gel. For purposes of this demonstration, we limited ourselves to 195 of the most prominent proteins. In the case of the inhibition effect that slows the growth of cells once a monolayer is formed, our resulis are striking. Some 21 proteins are modulated in abundance by more than 5 standard deviations of the measurement accuracy. The method promises to provide interesting results in other experiments involving changes in the pattern of abundance of proteins expressed in cells. 


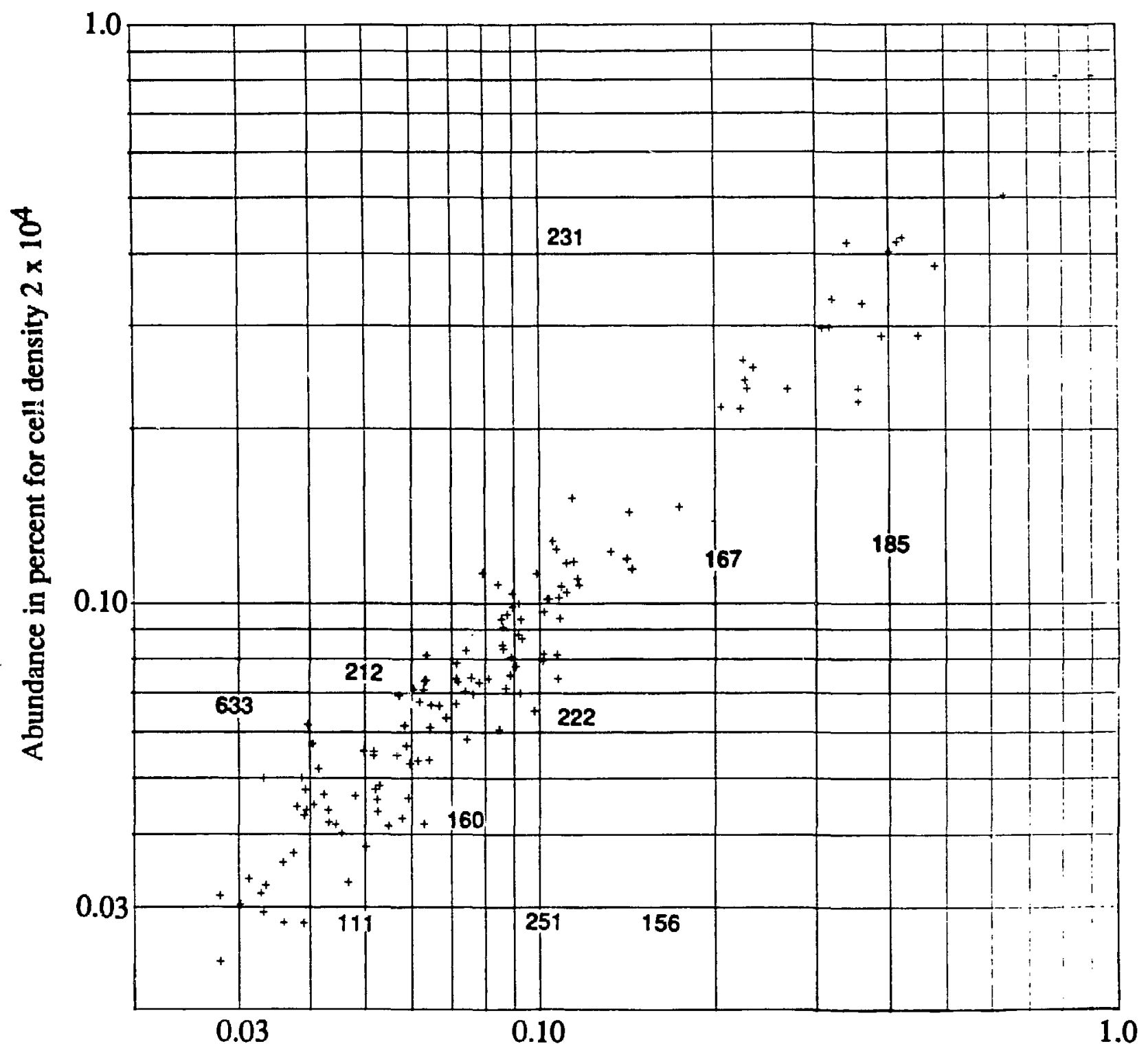

Abundance in percent for cell density $2 \times 10^{5}$

(a) Densities $2 \times 10^{4}$ and $2 \times 10^{5}$.

Fig. 7. Scatterplots comparing percent abundances of proteins from cells grown in 35 -mm-diameter culture dishes. For ratios $R \geq 1.6$ in the upper half, or $1 / R \geq 1.6$ in the lower half, the master peak number is printed out. 


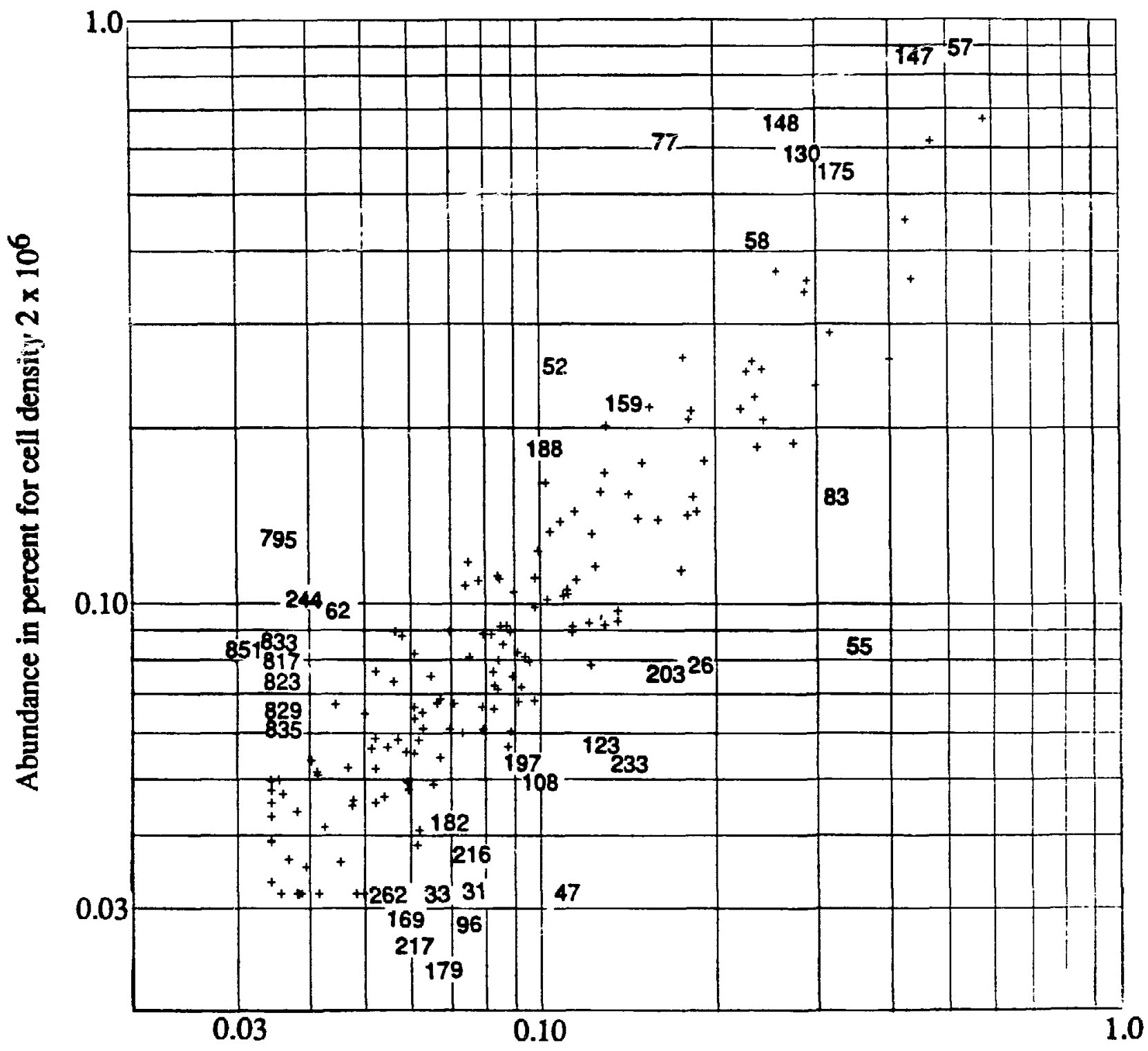

Abundance in percent for cell density $2 \times 10^{5}$

(b) Densities $2 \times 10^{6}$ and $2 \times 10^{5}$.

Fig. 7. Scatterplots comparing percent abundances of proteins from cells grown in 35-mm-diameter culture dishes. For ratios $R \geq 1.6$ in the upper half, or $1 / R \geq 1.6$ in the lower half, the master peak number is printed out. 


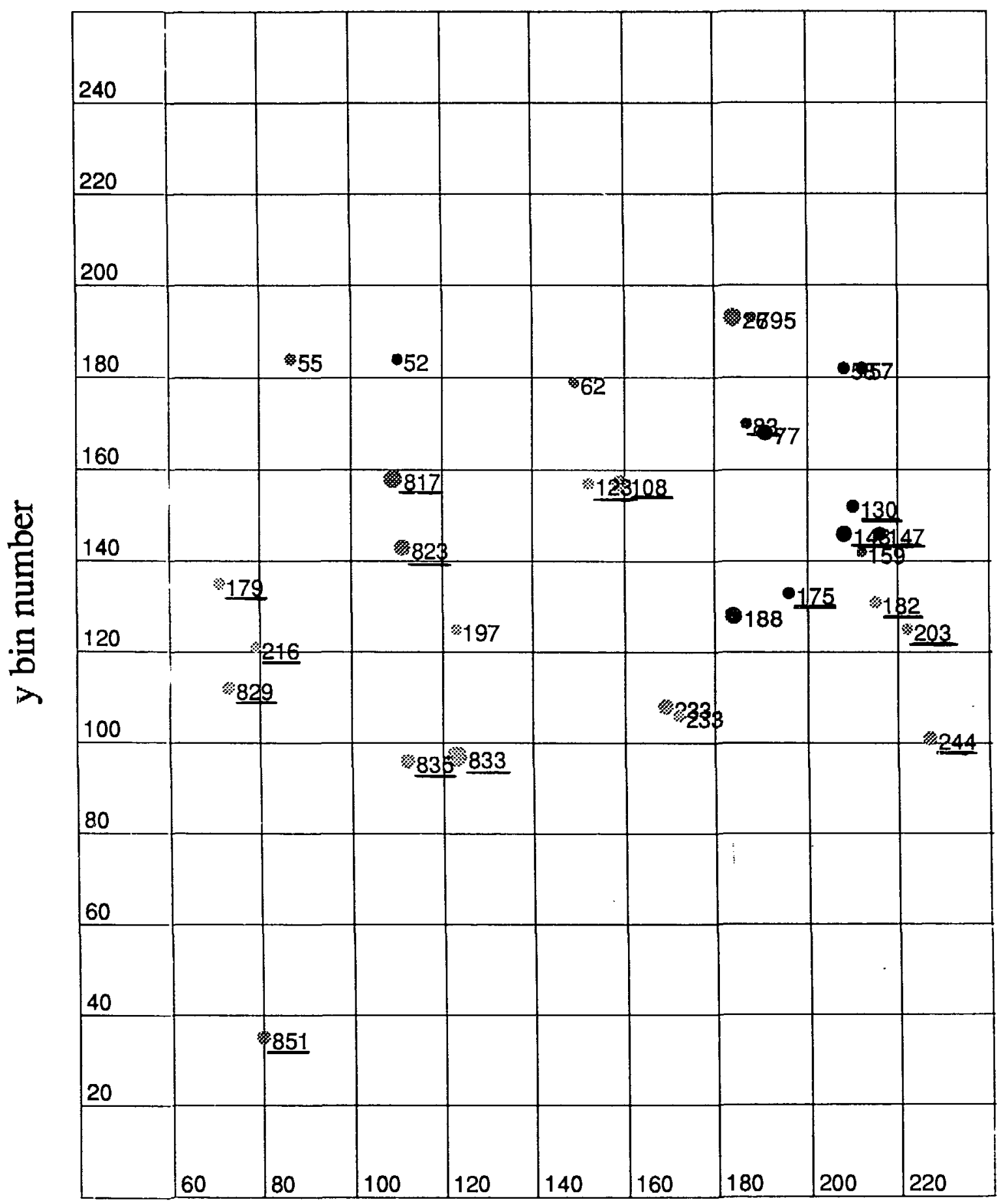

$\mathrm{x}$ bin number

Fig. 8. Spot graph giving the location of proteins from cells grown to a density of $2 \times 10^{5}$ and showing a density effect. Those with a 5-standard-deviation effect are underlined and listed in Tables $4 a$ and $4 b$. 
TABLE 4

PROTEINS MODULATED BY CONTACT INHIBITION

(a) Intensity Enhanced

\begin{tabular}{|c|c|c|c|c|c|c|c|c|c|c|}
\hline \multirow{2}{*}{$\begin{array}{c}\text { Master } \\
\text { Peak } \\
\text { No. } \\
96\end{array}$} & \multirow{2}{*}{$\begin{array}{r}\frac{B i n}{x} \\
b_{130}\end{array}$} & \multirow{2}{*}{$\frac{\begin{array}{c}\text { No. } \\
y\end{array}}{b_{166}}$} & \multirow{2}{*}{$\frac{\begin{array}{c}\text { Average } \\
\mathrm{pI}^{\mathrm{a}}\end{array}}{6.55}$} & \multirow{2}{*}{$\begin{array}{c}\begin{array}{c}\text { Average } \\
\text { Mol. Wt. } \\
(\mathrm{kg} / \text { mole })\end{array} \\
72\end{array}$} & \multicolumn{2}{|c|}{$\begin{array}{c}\text { Average } \\
\text { Abundance, } \\
\text { Cell } \\
\text { Density } \\
2 \times 10^{6} \\
\text { (parts } / 10^{5} \text { ) }\end{array}$} & \multicolumn{3}{|c|}{$\begin{array}{c}\text { Average } \\
\text { Abundance, } \\
\text { Cell } \\
\text { Density } \\
2 \times 10^{5} \\
\text { (parts } / 10^{5} \text { ) }\end{array}$} & $\begin{array}{l}\text { Abundance } \\
\text { Ratio, } \\
\text { Cell Density } \\
2 \times 10^{5} / 2 \times 10^{6}\end{array}$ \\
\hline & & & & & $70.9 \pm$ & 2.0 & $<31.20$ & & & $>2.27 \pm 0.06$ \\
\hline 179 & 71 & 135 & 7.27 & 46 & 66.9 & 2.7 & 31.30 & \pm & 0.4 & $2.14 \pm 0.09$ \\
\hline 123 & 152 & 157 & 6.31 & 61 & $119.0=$ & $\pm \quad 4.8$ & 55.90 & \pm & 2.5 & $2.13 \pm 0.13$ \\
\hline 83 & 187 & 170 & 5.89 & 78 & 313.0 & \pm 19.0 & 150.00 & \pm & 11.0 & $2.09 \pm 0.20$ \\
\hline 203 & 222 & 125 & 5.17 & 42 & 152.0 & $\pm \quad 8.8$ & 73.50 & \pm & 2.9 & $2.06 \pm 0.15$ \\
\hline 216 & 79 & 121 & 7.16 & 40 & 70.3 & 4.2 & 36.40 & \pm & 1.6 & $1.93 \pm 0.14$ \\
\hline 108 & 159 & 157 & 6.21 & 62 & 93.0 & 3.5 & 48.50 & \pm & 3.0 & $1.92 \pm 0.14$ \\
\hline 217 & $\mathrm{~b}_{40}$ & $b_{121}$ & 7.73 & 39 & 57.2 & 3.5 & $<3.12$ & & & $>1.83 \pm 0.11$ \\
\hline 182 & 215 & 131 & 5.33 & 44 & $66.0=$ & 3.5 & 40.10 & \pm & 2.0 & $1.65 \pm 0.12$ \\
\hline 262 & $b_{37}$ & $b_{87}$ & 7.82 & 30 & $50.4=$ & 2.6 & $<31.20$ & & & $>1.65 \pm 0.08$ \\
\hline
\end{tabular}

$\overline{\mathrm{a} I}=$ isoelectric point.

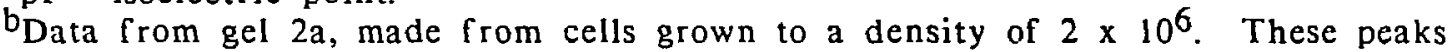
do not appear in Fig. 8.

(b) Intensity Diminished

\begin{tabular}{|c|c|c|c|c|c|c|c|}
\hline $\begin{array}{l}\text { Master } \\
\text { Peak } \\
\text { No. }\end{array}$ & $\begin{array}{l}\text { Bin } \\
x\end{array}$ & $\begin{array}{r}\text { No. } \\
y\end{array}$ & $\begin{array}{c}\text { Average } \\
\mathrm{pI}^{\mathrm{a}}\end{array}$ & $\begin{array}{l}\text { Average } \\
\text { Mol. Wt. } \\
\text { (kg/mole) }\end{array}$ & $\begin{array}{c}\text { Density } \\
2 \times 10^{6} \\
(\text { parts/105) }\end{array}$ & $\begin{array}{c}\text { Density } \\
2 \times 10^{5} \\
\left.\text { (parts } / 10^{5}\right)\end{array}$ & $\begin{array}{c}\text { Ratio, } \\
\text { Cell Density } \\
2 \times 10^{5} / 2 \times 10^{6}\end{array}$ \\
\hline 148 & 208 & 146 & 5.48 & 52 & $246.0 \pm 16.0$ & $651.0 \pm 29.0$ & $2.65 \pm 0.21$ \\
\hline 244 & 227 & 101 & 5.04 & 34 & $39.0 \pm 3.1$ & $97.7 \pm 4.1$ & $2.51 \pm 0.22$ \\
\hline 833 & 123 & 97 & 6.62 & 33 & $<33.6$ & $81.5 \pm 6.5$ & $>2.43 \pm 0.19$ \\
\hline 851 & 80 & 35 & 7.12 & 19 & $<33.6$ & $81.1 \pm 5.4$ & $>2.42 \pm 0.16$ \\
\hline 817 & 109 & 158 & 6.82 & 63 & $<33.6$ & $78.4 \pm 5.7$ & $>2.34 \pm 0.17$ \\
\hline 130 & 210 & 152 & 5.45 & 56 & $265.0 \pm 14.0$ & $575.0 \pm 33.0$ & $2.17 \pm 0.17$ \\
\hline 823 & 111 & 143 & 6.77 & 50 & $<33.6$ & $71.6 \pm 4.6$ & $>2.14 \pm 0.14$ \\
\hline 147 & 216 & 146 & 5.30 & 52 & $415.0 \pm 18.0$ & $858.0 \pm 17.0$ & $2.07 \pm 0.10$ \\
\hline 829 & 73 & 112 & 7.22 & 37 & $<33.6$ & $64.0 \pm 5.1$ & $>1.91 \pm 0.15$ \\
\hline 835 & 112 & 96 & 6.76 & 33 & $<33.6$ & $60.0 \pm 3.0$ & $>1.78 \pm 0.09$ \\
\hline 175 & 196 & 133 & 5.74 & 45 & $301.0 \pm 11.0$ & $531.0 \pm 24.0$ & $1.76 \pm 0.10$ \\
\hline
\end{tabular}

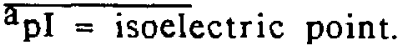




\section{ACKNOWLEDGMENTS}

This project began in March 1983. The design of the chamber, the dataacquisition hardware, and the associated software by W. W. Kinnison, J. W. Lillberg and $R$. J. McKee has been described in Ref. 13. Here, we acknowledge the help and useful advice of Professor S. Fukui of Nagoya University, of Dr. W. S. Williams of the University of Oxford, and of Alex Zehnder of SIN (Switzerland), who came to work with us at intervals. We are also indebted to $\mathrm{Mr}$. Ed Bush for the magnet modification and the mount that made the magnet removable. The biological experiments and the preparation of the gels were carried out at the Eleanor Roosevelt Institute for Cancer Research with the aid of Stan Nieisen and Robert Johnson. Mark Peters and Wendy Tiee in Los Alamo: operated the apparatus and analyzed the data. Special thanks are due to Dr. Nicholas Metropolis, who brought together Drs. Puck and Anderson to design a solution to the problem of eliminating autoradiography in the analysis of $2 \mathrm{D}$ protein gels.

\section{REFERENCES}

1. P. H. O'Farrell, J. Biol. Chem. 250, 4007-4021 (1975).

2. J. I. Garrels, J. Biol Chem. 254; 7961-7977 (1979).

3. R. Duncan, and J. W. B. Hershey, Anal. Biochem. 138, 144-145 (1984).

4. A. Breskin, G. Charpak, S. Demierre, S. Majewski, A. Policarpo, F. Sauli, and J. C. Santiard, Nucl. Inst. and Meth. 143, 29-39 (1977).

5. N. L. Anderson, J. Taylor, A. E. Scandora, B. P. Coulter, and N. G. AnJerson, Clin. Chem. 27, 1807-1820 (1981).

6. P. F. Lemkin and L. E. Lipkin, Comput. Biomed. Res. 13, 751, and 14, 355-380 (1981).

7. K.-P. Vo, M. J. Miller, E. P. Geiduschek, C. Nielsen, A. Olson, and N.-H. Xuoung, Anal. Biochem. 112, 258-271 (1981).

8. M. J. Miller, A. D. Olsen, and S. S. Thorgeirsson, Electrophoresis 5, 297-303 (1984).

9. M. M. Skolnick, S. R. Sternberg, and J. V. Neel, Clin. Chem. 28, 969-978 (1982).

10. M. J. Miller, Expl. Biol. Med. 11, 235-260 (1986).

11. See, for example, H. J. J. Braddick, The Physics of the Experimental Method (Chapman and Hall, London, 1966). 
12. G. Rumsdy and T. T. Puck, J. Cell. Physiology 111, 133-139 (1982).

13. J. W. Lillberg, W. W. Kinnison, R. J. McKee, and H. L. Anderson, Nucl. Inst. and Meth. A252, 251-254 (1986). 